\title{
Efeito da suplementação na composição física e centesimal da paleta, do costilhar e do pescoço de cordeiros Santa Inês terminados em pastejo
}

\author{
[Feeding supplementation effect on physical and chemical composition of shoulder, ribs, and neck \\ of Santa Inês lambs finished on pasture] \\ J.R.S. Santos ${ }^{1}$, J.M. Pereira Filho ${ }^{1}$, A.M.A. Silva ${ }^{1}$, M.F. Cezar ${ }^{1}$, J.B. Borburema ${ }^{2}$, J.O.R. Silva ${ }^{2}$ \\ ${ }^{1}$ Centro de Saúde e Tecnologia Rural - UFCG \\ Caixa Postal 64 \\ 58708-110 - Patos, PB \\ ${ }^{2}$ Aluno de graduação - CSTR-UFCG - Patos, PB
}

\begin{abstract}
RESUMO
Avaliou-se o efeito da suplementação sobre a composição físico-química da paleta, do costilhar e do pescoço de ovinos Santa Inês, terminados em pastejo. Foram utilizados 24 ovinos castrados, com peso vivo (PV) médio inicial de $15,8 \mathrm{~kg}$, distribuídos em três tratamentos $(0,1,0$ e 1,5\% do PV em suplementação concentrada). O delineamento experimental foi o inteiramente casualizado, com três tratamentos e oito repetições. A paleta, o costilhar e o pescoço foram dissecados em músculo, ossos e gordura para determinação da composição física, e a carne foi submetida à determinação da composição química. Observou-se efeito significativo $(\mathrm{P}<0,05)$ da suplementação de 1,0 e 1,5\% sobre o rendimento muscular, a relação músculo:osso e os teores de matéria seca e de gordura da carne. Os maiores rendimentos musculares foram observados na paleta e no costilhar com médias de 439,21 e 678,97g e de 377,30 e 693,01g, respectivamente, para suplementação de 0\% e 1,5\%.
\end{abstract}

Palavras-chave: ovino, semiárido, gordura, músculo, cortes comerciais

\begin{abstract}
The effect of supplementation on the physicochemical composition of shoulder, ribs, and neck of Santa Inês lambs finished on pasture was evaluated. A total of 24 castrated sheep, averaging $15.8 \mathrm{~kg}$ BW were used. The animals were allotted in a completely randomized design with three treatments (daily concentrated supplementation equivalent to 0, 1.0, and $1.5 \%$ of $B W$ ) and eight repetitions. The shoulder blade, ribs, and neck were dissected into muscle, bone, and fat to determine the physical composition and the meat was underwent to determination of chemical composition. There was a significant effect $(P<0.05)$ of the supplementation of 1.0 and $1.5 \%$ on muscle yield, muscle: bone ratio, and dry matter and fat contents of meat. The highest muscle yields were observed in the shoulder and ribs with averages of 439.21 and $678.97 \mathrm{~g}$ and 377.30 and $693.01 \mathrm{~g}$, respectively, for supplementation of $0 \%$ and $1.5 \%$.
\end{abstract}

Keywords: lamb, semi-arid, fat, muscle, commercial cuts

\section{INTRODUÇÃO}

O mercado exige um produto com máxima produção de músculos (fração comestível) e uma quantidade aceitável de gordura que mantenha as propriedades organolépticas da carne. A categoria animal que oferece máxima relação entre músculo e gordura é o cordeiro quando abatido com peso vivo entre 30 e $35 \mathrm{~kg}$. Para atingir este peso, tem sido adotada a prática do confinamento, devido ao baixo ganho de peso pelos ovinos em pastejo. Todavia, Santello et al. (2006) afirmaram que a terminação de cordeiros deve ser feita em sistema de pastejo com suplementação, devido ao fato de a análise econômica não ser favorável ao confinamento. Neste âmbito, a suplementação de cordeiros, em pastejo, pode garantir peso vivo, características de carcaça e cortes comerciais que atendam as exigências do consumidor.

Recebido em 9 de setembro de 2009

Aceito em 2 de agosto de 2010

E-mail: jromulosmedvet@hotmail.com

Apoio: $\mathrm{CNPq}$ 
A literatura enfatiza a composição física e centesimal da perna e do lombo, pois são cortes nobres (Garcia et al., 2003; Almeida Jr. et al., 2004). Mas também é necessário estudar os outros cortes comerciais, pois constituem uma fração significativa da carcaça que é aceita pela população de menor poder aquisitivo. Reis et al. (2001) destacam a paleta e o costilhar como cortes de segunda e o pescoço como corte de terceira qualidade. Essa literatura avalia as características dos cortes em condição de confinamento e com raças especializadas na produção de carne, como Suffolk e Dorper (Oliveira et al., 2002; Almeida Jr. et al., 2004).

Considerando-se que a composição química e a constituição física dos cortes são características importantes para determinar o mérito dos métodos de manejo de produção (Shadnoush et al., 2004) e que são necessárias pesquisas que avaliem a composição física e química dos cortes de segunda e terceira categoria em condições de pastejo com suplementação, especialmente no semiárido, o objetivo deste estudo foi avaliar o efeito da suplementação na composição física e centesimal da paleta, do costilhar e do pescoço em ovinos Santa Inês, terminados em pastejo.

\section{MATERIAL E MÉTODOS}

O experimento foi realizado, em sua fase de campo, entre os meses de agosto a outubro, na Fazenda Experimental Lameirão pertencente à Universidade Federal de Campina Grande, em Santa Teresinha-PB, na mesorregião do sertão paraibano. O clima da região, segundo a classificação de Köppen, é do tipo BSH'w (quente e seco), caracterizado por duas estações bem definidas, uma chuvosa (janeiro a junho) e outra seca (julho a dezembro). A temperatura anual média é de $26,8^{\circ} \mathrm{C}$, com umidade relativa de $61 \%$. A precipitação média anual é de 500mm (Brasil, 1992).
Foram utilizados 24 ovinos machos da raça Santa Inês, castrados, com média de peso vivo (PV) inicial de $15,8 \mathrm{~kg} \pm 1,4 \mathrm{~kg}$ e idade variando entre três e quatro meses. A distribuição dos animais nos tratamentos $(0,1$ e $1,5 \%$ do $\mathrm{PV}$ em suplementação com concentrado) foi feita em grupos de três, um para cada tratamento até atingir oito repetições. Os animais foram submetidos a um período pré-experimental de 21 dias, no qual foram identificados por meio de colar e tatuagem na orelha. Neste período, os animais foram vermifugados e receberam $1 \mathrm{~mL}$ de vitaminas ADE (vit.A: 20.000.000UI, vit.D3: 5.000.000UI, vit.E: 5.500UI).

Os animais tinham acesso, diariamente, à pastagem das sete às $16 \mathrm{~h}$, quando eram recolhidos, para receber a suplementação em baias equipadas com comedouros individuais $\mathrm{e}$ bebedouros. As dietas experimentais foram constituídas por pastagem nativa enriquecida com capim-buffel (Cenchrus ciliaris L cv. Biloela) ad libitum e níveis crescentes de suplementação concentrada.

$\mathrm{O}$ concentrado foi à base de milho moído $(40,4 \%)$, farelo de soja $(56,6 \%)$ e mistura mineral (3\%), ajustada de modo que a dieta com maior proporção de concentrado atendesse as exigências de proteína bruta e de energia metabolizável, preconizadas pelo AFRC (Energy..., 1993) para um ganho médio de peso diário de $200 \mathrm{~g}$.

Os ingredientes das rações foram analisados quanto aos teores de matéria seca, proteína bruta, fibra em detergente neutro, fibra em detergente ácido, energia bruta e cinzas, de acordo com as metodologias descritas por Silva e Queiroz (2002). A composição química da forragem disponível e dos ingredientes farelo de soja e milho moído é apresentada na Tab. 1.

Tabela 1. Composição química da forragem disponível e dos ingredientes farelo de soja e milho moído

\begin{tabular}{lcccccc}
\hline \multirow{2}{*}{ Ingredientes } & \multirow{2}{*}{ MS (\%) } & \multirow{2}{*}{ EB kcal/kgMS) } & \multicolumn{4}{c}{$\%$ na MS } \\
\cline { 3 - 7 } & & & PB & FDN & FDA & Cinzas \\
\hline Farelo de soja & 91,64 & 5310 & 45,96 & 7,90 & 3,82 & 7,27 \\
Fubá de milho & 90,02 & 5670 & 9,73 & 9,00 & 4,01 & 6,02 \\
Gramíneas* & 66,54 & 4479 & 4,08 & 79,27 & 49,32 & 7,30 \\
Gramíneas** & 66,35 & 4493 & 2,80 & 80,79 & 52,71 & 7,66 \\
Dicotiledôneas* & 50,63 & 4418 & 9,22 & 68,31 & 45,75 & 6,70 \\
Dicotiledôneas** & 68,54 & 4633 & 3,76 & 77,47 & 54,50 & 3,64 \\
\hline
\end{tabular}

*inicio do experimento; **final do experimento. 
A mistura mineral utilizada no concentrado foi constituída de $1,1 \%$ de calcário calcítico, $39 \%$ de fosfato bicálcico, $0,01 \%$ de iodato de potássio, $1 \%$ de sulfato de manganês, $0,5 \%$ de sulfato de zinco, $0,005 \%$ de selenito de sódio, $0,211 \%$ de sulfato de cobre, $0,047 \%$ de sulfato de cobalto e $47,127 \%$ de sal comum.

A cada 14 dias, os cordeiros eram pesados e, quando o animal do maior nível de suplementação de cada grupo de três atingia $30 \mathrm{~kg}$ de PV, o grupo era abatido. Antes do abate, os animais eram submetidos a jejum sólido de $16 \mathrm{~h}$ e hídrico de $14 \mathrm{~h}$. Os animais foram abatidos mediante atordoamento e sangria feita por um corte nas artérias carótidas e nas veias jugulares externas.

Após a sangria, foram feitas a retirada da pele, a evisceração e a retirada da cabeça, da cauda e das patas, obtendo-se a carcaça, que foi levada para câmara fria com temperatura de $5^{\circ} \mathrm{C}$ por 24h. As carcaças foram seccionadas longitudinalmente, e das meias carcaças esquerdas foram retirados a paleta, o costilhar e o pescoço que, então, foram congelados a $-20^{\circ} \mathrm{C}$ para posterior dissecação, de acordo com metodologia descrita por Cezar e Sousa (2007).
A dissecação dos cortes comerciais foi feita em sala climatizada, os cortes foram descongelados, pesados e dissecados em: músculo, osso, gordura subcutânea e gordura intermuscular, as quais foram somadas para quantificar o total de gordura (Cezar e Sousa, 2007). Os resultados foram expressos em peso absoluto e em relação ao peso do respectivo corte. Também foram determinadas as relações entre o peso dos músculos e o peso da gordura total, bem como a relação entre o peso dos músculos e o peso dos ossos de cada corte. A carne (músculo) foi triturada, homogeneizada e foram retiradas amostras para determinação da matéria seca, da gordura (extrato etéreo), da proteína bruta e da matéria mineral, conforme metodologias descritas por Silva e Queiroz (2002).

O delineamento experimental foi o inteiramente ao acaso, com três tratamentos e oito repetições. Os dados foram submetidos à análise de variância e as médias comparadas pelo teste Tukey a 5\% de probabilidade, por meio dos procedimentos Proc Glm do SAS/1999.

\section{RESULTADOS E DISCUSSÃO}

Embora não tenham sido objeto de estudo neste trabalho, os dados de desempenho dos ovinos são apresentados na Tab. 2.

Tabela 2. Desempenho de ovinos Santa Inês submetidos a três níveis de suplementação em pastejo

\begin{tabular}{lccc}
\hline Item & \multicolumn{3}{c}{ Nível de suplementação (\% do PV) } \\
\cline { 2 - 4 } & 0 & 1,0 & 1,5 \\
\hline Ganho de peso médio diário $(\mathrm{g})$ & 77,0 & 134,0 & 190,0 \\
Peso ao abate $(\mathrm{kg})$ & 20,5 & 23,6 & 27,1 \\
Consumo $(\mathrm{g} / \mathrm{kg} 0,75 /$ dia) & & & \\
$\quad$ Matéria seca & 60,7 & 66,4 & 75,3 \\
Proteína bruta & 4,0 & 10,2 & 15,9 \\
Fibra em detergente neutro & 43,2 & 38,6 & 35,5 \\
\hline
\end{tabular}

$\mathrm{Na}$ Tab. 3, são apresentados o peso, a proporção dos componentes do tecido da paleta e a composição centesimal da carne. Não houve efeito de suplementação $(\mathrm{P}>0,05)$ sobre o peso da gordura subcutânea, proporção de gordura total e gordura subcutânea, e relação músculo:gordura.

A proporção de ossos e o teor de gordura na carne diferiram $(\mathrm{P}<0,05)$ entre os tratamentos, com menor proporção de osso e maior de gordura nos animais do tratamento com $1,5 \%$ de suplementação. $\mathrm{O}$ rendimento muscular no tratamento com $1,5 \%$ de suplementação foi maior que o obtido nos animais não suplementados. Cada tecido apresenta impulso de crescimento distinto em determinada fase da vida do animal, os animais nascem com determinada composição física que se altera durante o seu desenvolvimento. O tecido ósseo é de desenvolvimento precoce, o muscular intermediário, e o adiposo tardio; à medida que os tecidos muscular e adiposo aumentam sua participação proporcional na carcaça, diminui a proporção do tecido ósseo, o mesmo é valido para os cortes comerciais (Butterfield, 1988). 
O maior teor de gordura da carne da paleta no tratamento com $1,5 \%$ de suplementação se deveu ao maior consumo energético, o que está de acordo com Zeola et al. (2004) e Garcia et al. (2003). A proporção de gordura da carne depende da necessidade energética do animal e do balanço energético da dieta, podendo chegar a teores acima de 20\% (Zamiri e Izadifard, 1997). Carnes com teor de gordura menor que 5\% são consideradas magras (Gutler el al., 1987).

O peso dos músculos e a relação músculo:osso foram iguais para os tratamentos 0 e 1,0\%, ocorrendo variação significativa em relação ao tratamento $1,5 \%$. O nível de suplementação $1 \%$ não promoveu melhora na deposição muscular, todavia o rendimento muscular apresentou valor intermediário. Como a paleta é um corte de segunda, sendo assim acessível financeiramente para classes de menor poder aquisitivo, o peso e o rendimento dos músculos tomam maior importância, uma vez que representa a parte comestível de maior interesse pelo consumidor (Reis et al., 2001).

Tabela 3. Médias e coeficientes de variação (CV) do peso e rendimento dos tecidos, das relações músculo:gordura (RMG) e músculo:osso (RMO) e da composição centesimal da paleta de ovinos Santa Inês submetidos a três níveis de suplementação em pastejo

\begin{tabular}{lcccc}
\hline Item & \multicolumn{2}{c}{ Nível de suplementação (\% do PV) } & \multirow{2}{*}{ CV (\%) } \\
\cline { 2 - 4 } & 0 & 1,0 & 1,5 & \\
\hline Paleta (g) & $694,12 \mathrm{~b}$ & $790,71 \mathrm{~b}$ & $1007,10 \mathrm{a}$ & 12,40 \\
Músculos (g) & $439,21 \mathrm{~b}$ & $513,06 \mathrm{~b}$ & $678,97 \mathrm{a}$ & 13,88 \\
Ossos (g) & $226,09 \mathrm{~b}$ & $239,45 \mathrm{ab}$ & $275,71 \mathrm{a}$ & 12,03 \\
Gordura total (g) & $28,82 \mathrm{~b}$ & $38,2 \mathrm{ab}$ & $52,42 \mathrm{a}$ & 28,55 \\
Gordura subcutânea (g) & $20,75 \mathrm{a}$ & $24,10 \mathrm{a}$ & $29,98 \mathrm{a}$ & 33,44 \\
Gordura intermuscular (g) & $8,07 \mathrm{~b}$ & $14,15 \mathrm{ab}$ & $22,43 \mathrm{a}$ & 45,21 \\
Músculos (\%) & $63,12 \mathrm{~b}$ & $64,88 \mathrm{ab}$ & $67,32 \mathrm{a}$ & 2,85 \\
Ossos (\%) & $32,75 \mathrm{a}$ & $30,23 \mathrm{~b}$ & $27,45 \mathrm{c}$ & 5,94 \\
Gordura total (\%) & $4,13 \mathrm{a}$ & $4,88 \mathrm{a}$ & $5,23 \mathrm{a}$ & 27,11 \\
Gordura subcutânea (\%) & $2,98 \mathrm{a}$ & $3,06 \mathrm{a}$ & $3,02 \mathrm{a}$ & 30,15 \\
Gordura intermuscular (\%) & $1,14 \mathrm{~b}$ & $1,82 \mathrm{ab}$ & $2,21 \mathrm{a}$ & 43,35 \\
RMG (g/g) & $15,45 \mathrm{a}$ & $15,26 \mathrm{a}$ & $13,46 \mathrm{a}$ & 30,16 \\
RMO (g/g) & $1,94 \mathrm{~b}$ & $2,15 \mathrm{~b}$ & $2,46 \mathrm{a}$ & 8,18 \\
Matéria seca (\%) & $19,82 \mathrm{~b}$ & $23,54 \mathrm{a}$ & $24,23 \mathrm{a}$ & 7,59 \\
Cinzas (\%) & $0,93 \mathrm{ab}$ & $1,00 \mathrm{a}$ & $0,91 \mathrm{~b}$ & 7,04 \\
Proteína bruta (\%) & $17,72 \mathrm{~b}$ & $19,79 \mathrm{a}$ & $18,88 \mathrm{ab}$ & 7,11 \\
Gordura (\%) & $1,17 \mathrm{c}$ & $2,75 \mathrm{~b}$ & $4,44 \mathrm{a}$ & 30,98 \\
\hline
\end{tabular}

Médias seguidas de letras diferentes, na mesma linha, diferem entre si $(\mathrm{P}<0,05)$.

O peso dos ossos, da gordura total, da gordura intermuscular e a proporção de gordura intermuscular diferiram entre o tratamento $0 \mathrm{e}$ $1,5 \%$, não havendo significância de ambos em relação ao tratamento $1,0 \%$.

A matéria seca da carne da paleta não diferiu $(\mathrm{P}>0,05)$ entre os tratamentos com 1,0 e $1,5 \%$ de suplementação, porém ambos diferiram do tratamento $0 \%$. A proteína bruta da paleta diferiu entre os tratamentos 0 e 1,0\%, mas não houve significância $(\mathrm{P}>0,05)$ em relação ao tratamento $1,5 \%$. A proteína é o principal componente orgânico da carne, e o que menos varia, apresentando teores em torno de 20\%. As variações nos teores de proteína são devido ao tipo de alimentação oferecida aos animais (Gutler el al., 1987), aspecto que pode ser observado para a carne da paleta. Isso pode ser reflexo do elevado metabolismo basal dos animais não suplementados que não mobilizaram nutrientes em quantidade adequada para formação muscular em virtude da atividade de pastejo, explicando em parte o menor valor de proteína bruta. Shadnoush et al. (2004) afirmaram que dietas com volumosos de boa qualidade resultam em menor custo de produção, mas podem não atender as exigências de animais em pastejo, reforçando a necessidade de suplementação. 
A matéria mineral da carne da paleta diferiu entre os tratamentos 1,0 e 1,5\%, mas não houve significância $(\mathrm{P}>0,05)$ em relação ao tratamento $0 \%$. Este resultado confirma a premissa de que, em termos de composição centesimal, as cinzas apresentam comportamento inversamente proporcional ao da gordura; fato também observado nos resultados obtidos por Zapata et al. (2001).

Na Tab. 4, são descritos os resultados de peso, proporção dos componentes teciduais $\mathrm{e}$ composição centesimal da carne do costilhar. Constatou-se que não houve significância $(P>0,05)$ entre os tratamentos para percentual de gordura intermuscular, para matéria mineral e proteína bruta do costilhar. A suplementação promoveu incremento no peso dos músculos, para o teor de gordura e matéria seca da carne do costilhar, com o nível de suplementação 1,5\% promovendo maiores valores. Observaram-se maiores valores de matéria seca para o nível de suplementação $1,5 \%$, refletindo os resultados obtidos para o teor de gordura nos respectivos tratamentos.

O peso dos ossos, da gordura total, da gordura subcutânea e a proporção de gordura subcutânea do costilhar não foram influenciados pela suplementação nos tratamentos com 0 e $1,0 \%$ $(\mathrm{P}>0,05)$, entretanto ambos diferiram $(\mathrm{P}<0,05)$ do tratamento com 1,5\%. A separação da gordura durante dissecação é dificultosa, o que gera altos coeficientes de variação para peso e rendimento, como os observados neste trabalho, todavia é o método mais utilizado para sua avaliação nos cortes comerciais (Cezar e Sousa, 2007).

Tabela 4. Médias e coeficientes de variação (CV) do peso e rendimento dos tecidos, das relações músculo:gordura (RMG) e músculo:osso (RMO) e da composição centesimal do costilhar de ovinos Santa Inês submetidos a três níveis de suplementação em pastejo

\begin{tabular}{lcccc}
\hline Item & \multicolumn{2}{c}{ Nível de suplementação (\% do PV) } & \multirow{2}{*}{ CV $(\%)$} \\
\cline { 2 - 4 } & 0 & 1,0 & 1,5 & \\
\hline Costilhar & $771,78 \mathrm{c}$ & $1060,24 \mathrm{~b}$ & $1320,96 \mathrm{a}$ & 9,41 \\
Músculos (g) & $377,30 \mathrm{c}$ & $565,42 \mathrm{~b}$ & $693,01 \mathrm{a}$ & 11,81 \\
Ossos (g) & $354,54 \mathrm{~b}$ & $410,91 \mathrm{~b}$ & $488,58 \mathrm{a}$ & 10,54 \\
Gordura total (g) & $39,94 \mathrm{~b}$ & $83,91 \mathrm{~b}$ & $139,37 \mathrm{a}$ & 37,06 \\
Gordura subcutânea (g) & $12,35 \mathrm{~b}$ & $35,73 \mathrm{~b}$ & $75,56 \mathrm{a}$ & 45,26 \\
Gordura intermuscular (g) & $27,59 \mathrm{~b}$ & $48,18 \mathrm{ab}$ & $63,80 \mathrm{a}$ & 37,10 \\
Músculos (\%) & $48,70 \mathrm{~b}$ & $53,25 \mathrm{a}$ & $52,44 \mathrm{a}$ & 5,0 \\
Ossos (\%) & $46,19 \mathrm{~b}$ & $38,82 \mathrm{a}$ & $37,03 \mathrm{a}$ & 7,89 \\
Gordura total (\%) & $5,11 \mathrm{~b}$ & $7,92 \mathrm{ab}$ & $10,53 \mathrm{a}$ & 32,95 \\
Gordura subcutânea (\%) & $1,52 \mathrm{~b}$ & $3,29 \mathrm{~b}$ & $5,70 \mathrm{a}$ & 43,36 \\
Gordura intermuscular (\%) & $3,59 \mathrm{a}$ & $4,64 \mathrm{a}$ & $4,82 \mathrm{a}$ & 36,56 \\
RMG (g/g) & $9,7 \mathrm{~b}$ & $7,49 \mathrm{ab}$ & $5,42 \mathrm{a}$ & 27,79 \\
RMO (g/g) & $1,06 \mathrm{~b}$ & $1,37 \mathrm{a}$ & $1,43 \mathrm{a}$ & 11,44 \\
Matéria seca (\%) & $21,06 \mathrm{c}$ & $24,67 \mathrm{~b}$ & $27,49 \mathrm{a}$ & 6,92 \\
Cinzas (\%) & $0,73 \mathrm{a}$ & $0,65 \mathrm{a}$ & $0,70 \mathrm{a}$ & 12,18 \\
Proteína bruta (\%) & $19,3 \mathrm{a}$ & $21,31 \mathrm{a}$ & $22,18 \mathrm{a}$ & 8,64 \\
Gordura (\%) & $1,03 \mathrm{c}$ & $2,71 \mathrm{~b}$ & $4,61 \mathrm{a}$ & 41,23 \\
\hline
\end{tabular}

Médias seguidas de letras diferentes, na mesma linha, diferem entre si $(\mathrm{P}<0,05)$.

O rendimento dos músculos e dos ossos assim como a relação músculo:osso do costilhar não diferiram entre $(\mathrm{P}>0,05)$ os tratamentos $1,0 \mathrm{e}$ $1,5 \%$, porém ambos diferiram do tratamento $0 \%$. O rendimento muscular é uma importante variável, tendo em vista que dele dependem o crescimento relativo dos ossos e da gordura; como o rendimento muscular foi estatisticamente semelhante entre os níveis de suplementação 1,0 e $1,5 \%$, ambos seriam indicados quando o objetivo é o máximo rendimento. $\mathrm{O}$ peso da gordura intermuscular, a proporção de gordura total e a relação músculo:gordura do costilhar diferiram entre os tratamentos 0 e $1,5 \%$, mas não houve significância $(\mathrm{P}>0,05)$ em relação ao tratamento $1,0 \%$.

Destaca-se que os níveis de suplementação $1 \%$ e $1,5 \%$ promoveram maiores valores para o peso do tecido muscular quando comparado com os 
animais que não foram suplementados, o que se pode confirmar com os maiores valores obtidos para relação músculo:osso nos tratamentos com 1 e 1,5\% de suplementação (Tab. 4).

De acordo com Rosa et al. (2002), a gordura é o tecido de maior variabilidade no organismo animal, seja do ponto de vista quantitativo, seja por sua distribuição e função biológica fundamental de armazenamento de energia para períodos de escassez alimentar, sendo seu aumento representado pelo balanço energético positivo na dieta. Huidobro e Cañeque (1994) afirmaram que as proporções de gordura em cada depósito afetam o valor comercial da carcaça e dos cortes e que os principais sistemas de avaliação de carcaça são baseados em medições da gordura subcutânea.

Notou-se que o rendimento da gordura subcutânea foi maior no tratamento com $1,5 \%$ de suplementação. Isso significa que um aumento de $50 \%$ na suplementação pode tornar mais onerosa a produção, tendo em vista o direcionamento de nutrientes para deposição de gordura, tecido não apreciado pelo mercado consumidor, nem pelo açougueiro que perde na compra da carcaça, pois a gordura subcutânea não é repassada para o consumidor, sendo retirada no toilet.

$\mathrm{Na}$ Tab. 5, são apresentados os resultados referentes ao peso, à proporção dos componentes teciduais e à composição centesimal do pescoço. Observa-se que não houve diferença $(\mathrm{P}>0,05)$ entre os tratamentos para peso de ossos e de gordura subcutânea; para proporção de gordura total e de gordura subcutânea; para a relação músculo:gordura; para matéria seca, matéria mineral e proteína bruta (PB), todavia é importante destacar os altos coeficientes de variação para gordura total, gordura subcutânea e relação músculo:gordura. Os teores de proteína bruta e matéria mineral estão dentro dos intervalos descritos como normais por Gutler el al. (1987).

O peso dos músculos do pescoço, a proporção de ossos, a relação músculo:osso e o teor de gordura da carne diferiram entre os tratamentos 0 e 1,5\%, os quais foram semelhantes ao tratamento com $1,0 \%$ de suplementação.

Tabela 5. Médias e coeficientes de variação (CV) do peso e rendimento dos tecidos, das relações músculo:gordura (RMG) e músculo:osso (RMO) e da composição centesimal do pescoço de ovinos Santa Inês submetidos a três níveis de suplementação em pastejo

\begin{tabular}{lcccc}
\hline Item & \multicolumn{2}{c}{ Nível de suplementação (\% do PV) } & \multirow{2}{*}{ CV (\%) } \\
\cline { 2 - 4 } & 0 & 1,0 & 1,5 & 20,76 \\
Pescoço (g) & $221,99 \mathrm{~b}$ & $282,56 \mathrm{~b}$ & $376,44 \mathrm{a}$ & 21,73 \\
Músculos (g) & $112,72 \mathrm{~b}$ & $167,57 \mathrm{ab}$ & $220,11 \mathrm{a}$ & 23,92 \\
Ossos (g) & $87,00 \mathrm{a}$ & $93,02 \mathrm{a}$ & $114,61 \mathrm{a}$ & 35,72 \\
Gordura total (g) & $22,26 \mathrm{~b}$ & $21,98 \mathrm{~b}$ & $41,72 \mathrm{a}$ & 44,63 \\
Gordura subcutânea (g) & $18,36 \mathrm{a}$ & $15,13 \mathrm{a}$ & $27,95 \mathrm{a}$ & 36,88 \\
Gordura intermuscular (g) & $3,90 \mathrm{~b}$ & $6,84 \mathrm{~b}$ & $13,77 \mathrm{a}$ & 7,99 \\
Músculos (\%) & $50,70 \mathrm{~b}$ & $59,15 \mathrm{a}$ & $58,63 \mathrm{a}$ & 13,41 \\
Ossos (\%) & $39,45 \mathrm{a}$ & $33,05 \mathrm{ab}$ & $30,26 \mathrm{~b}$ & 30,97 \\
Gordura total (\%) & $9,84 \mathrm{a}$ & $7,79 \mathrm{a}$ & $11,10 \mathrm{a}$ & 39,49 \\
Gordura subcutânea (\%) & $7,99 \mathrm{a}$ & $5,34 \mathrm{a}$ & $7,43 \mathrm{a}$ & 27,94 \\
Gordura intermuscular (\%) & $1,84 \mathrm{~b}$ & $2,45 \mathrm{~b}$ & $3,67 \mathrm{a}$ & 36,44 \\
RMG (g/g) & $5,93 \mathrm{a}$ & $8,50 \mathrm{a}$ & $5,48 \mathrm{a}$ & 18,27 \\
RMO (g/g) & $1,33 \mathrm{~b}$ & $1,80 \mathrm{ab}$ & $1,97 \mathrm{a}$ & 11,66 \\
Matéria seca (\%) & $23,35 \mathrm{a}$ & $24,30 \mathrm{a}$ & $25,31 \mathrm{a}$ & 18,67 \\
Cinzas (\%) & $1,14 \mathrm{a}$ & $1,01 \mathrm{a}$ & $1,13 \mathrm{a}$ & 12,27 \\
Proteína bruta (\%) & $20,05 \mathrm{a}$ & $19,98 \mathrm{a}$ & $19,77 \mathrm{a}$ & 31,87 \\
Gordura (\%) & $2,16 \mathrm{~b}$ & $3,31 \mathrm{ab}$ & $4,41 \mathrm{a}$ & \\
\hline
\end{tabular}

Médias seguidas de letras diferentes, na mesma linha, diferem entre si $(\mathrm{P}<0,05)$.

Diaz et al. (2002) afirmaram que cordeiros terminados em pastejo, geralmente, têm menos gordura que cordeiros terminados em confinamento. Isso porque animais em pastejo têm maiores exigências de energia que animais confinados devido a um aumento no 
metabolismo basal pela presença de fibra na sua dieta e pelo aumento da atividade física associada ao pastejo, fato confirmado ao se comparar os teores de gordura desse experimento com os 32,7\% obtidos para carne de pescoço de ovinos em confinamento no trabalho realizado por Kashan et al. (2005).

Os tratamentos com 1,0 e $1,5 \%$ de suplementação promoveram melhora no rendimento muscular. $\mathrm{O}$ tratamento com $1,5 \%$ de suplementação promoveu maiores valores para peso da gordura total, peso da gordura intermuscular e para rendimento da gordura intermuscular. Notou-se ainda que o tratamento com $1,5 \%$ de suplementação promoveu uma deposição de gordura total que superou em quase duas vezes o peso em relação aos demais tratamentos. Quanto à gordura intermuscular, observou-se que foi maior para o tratamento $1,5 \%$, sendo mais que o dobro em relação ao tratamento $1 \%$ e 3,5 vezes maior que o tratamento sem suplementação. $\mathrm{O}$ rendimento da gordura intermuscular também foi mais evidente no tratamento $1,5 \%$ (Tab. 5).

Considerando a pouca aceitação de gordura pelos consumidores e a maior demanda energética para sua formação, pois uma maior deposição de gordura demanda uma dieta com balanço energético positivo, o que foi observado no tratamento com $1,5 \%$ de suplementação, ou seja, maior utilização de concentrado, e consequentemente aumento do custo de produção. Para esta situação, o tratamento com $1,0 \%$ de suplementação seria o indicado, tendo em vista que ele apresentou rendimento muscular semelhante ao de $1,5 \%$ com adequada deposição de gordura.

Ao se comparar os resultados deste trabalho com os observados por Silva e Pires (2000), percebese que a relação músculo:osso é maior em animais de raças especializadas para produzir carne, como a Texel. O fator confinamento e a aptidão para carne determinam maior deposição de gordura e consequentemente menor relação músculo:gordura. Animais em pastejo, geralmente, têm menor deposição de gordura quando comparados a animais em confinamento, o que lhes confere uma maior relação músculo:gordura.
Neste experimento, o aumento dos níveis de suplementação dos ovinos terminados em pastagem nativa não resultou em carnes gordas, pois os valores registrados para gordura intermuscular foram abaixo de 5\% (Gutler et al., 1987). Característica apreciada pelo mercado consumidor, segundo Thompson e Butterfield (1987), o excesso de gordura é fator limitante na produção de cordeiros mais pesados, sendo necessária a identificação de sistemas de produção capazes de produzir carcaças mais desejáveis, com maior rendimento muscular, sobretudo quando os animais são alimentados para atingirem pesos elevados.

\section{CONCLUSÕES}

A suplementação com concentrado, nos teores de 1,0 e $1,5 \%$ do preso vivo, melhora o rendimento muscular, as relações músculo:gordura $\mathrm{e}$ músculo:osso e a composição centesimal da carne da paleta, do pescoço e do costilhar de ovinos Santa Inês, terminados em pastejo.

\section{AGRADECIMENTO}

Ao Conselho Nacional de Desenvolvimento Científico e Tecnológico (CNPq), pelo apoio financeiro.

\section{REFERÊNCIAS BIBLIOGRÁFICAS}

ALMEIDA JÚNIOR, G.A; COSTA, C.; MONTEIRO, A. L. G; et al. Qualidade da carne de cordeiros, criados em creep feeding com silagem de grãos úmidos de milho. Rev. Bras. Zootec., v.33. p.1039-1047, 2004.

BRASIL. Secretaria Nacional de Irrigação. Departamento Nacional de Meteorologia. Normas Climatológicas: 1961-1990. Brasília: Embrapa-SPI, 1992. 84p.

BUTTERFIELD, R.M. New concept of sheep growth. Sydney: Sydney University, 1988. 167p.

CEZAR, M.F.; SOUZA, W.H. Carcaças ovinas e caprinas: obtenção, avaliação e classificação. Uberaba: Editora Agropecuária Tropical, 2007. $147 \mathrm{p}$.

DIAZ, M.T.; VELASCO, S.; CAÑEQUE, V. et al. Use of concentrate or pasture for fattening lambs and its effect on carcass and meat quality. Small Rum. Res., v.43, p.257-268, 2002. 
ENERGY and protein requirements of ruminants - AFRC. Wallingford: CAB International, 1993 (Technical Committee on Responses to Nutrients). 151p.

GARCIA, C.A.; MONTEIRO, A.L.G.; COSTA, C. et al. Medidas objetivas e composição tecidual da carcaça de cordeiros alimentados com diferentes níveis de energia em creep feeding. Rev. Bras. Zootec., v.32. p.1380-1390, 2003.

GUTLER, H.; KETZ, A.; KOLB, E. et al. Kolb: Fisiologia veterinária. 4.ed. Rio de Janeiro: Guanabara Koogan, 1987. 612p.

HUIDOBRO, F.R.; CAÑEQUE, V. Producción de carne en corderos de raza Manchega. II. Conformación y estado de engrasamiento de la canal y proporción de piezas en distintos tipos comerciales. Invest. Agrar. Prod. Sanid. Anim., v.8, p.233-243, 1993.

KASHAN， N.E.J.; MANAFI AZAR， G.H.; AFZALZADEH, A. et al. Growth performance and carcass quality of fattening lambs from fattailed and tailed sheep breeds. Small Rum. Res., v.60, p.267-271, 2005.

OSÓRIO, J.C.S.; OSÓRIO, M.T.M.; JARDIM, P.O. et al. Métodos para avaliação da produção da carne ovina: "in vivo", na carcaça e na carne. Pelotas: Editora Universitária, 1998. 107p.

OLIVEIRA, M.V.M.; PEREZ, J.R.O., ALVES, E.L. et al. Rendimento de carcaça, mensurações e peso de cortes comerciais de cordeiros Santa Inês e Bergamacia alimentados com dejetos de suínos em confinamento. Rev. Bras. Zootec., v.31, p.1451-1458, 2002.

REIS, W.; JOBIM, C.C.; MACEDO, F.A.F. et al. Características da carcaça de cordeiros alimentados com dietas contendo grãos de milho conservados em diferentes formas. Rev. Bras. Zootec., v.30, p.1308-1315, 2001.

ROSA, G.T.; PIRES, C.P.; SILVA, J.H.S. et al. crescimento de osso, músculos e gordura dos cortes da carcaça de cordeiros e cordeiras em diferentes métodos de alimentação. Rev. Bras. Zootec., v.31, p.2283-2289, 2002.
SANTELLO, G.A.; MACEDO, F.A.F.; MEXIA, A.A. et al. Características de carcaça e análise do custo de sistemas de produção de cordeiros $1 / 2$ Dorset Santa Inês. Rev. Bras. Zootec., v.35, supl.2, p.1852-1859, 2006.

SHADNOUSH, G.H.; GHORBANI, G.R.; EDRIS, M.A. Effect of different energy levels in feed and slaughter weights on carcass and chemical composition of Lori-Bakhtiari ram lambs. Small Rum. Res., v.51, p.243-249, 2004.

SILVA, L.F.; PIRES, C.C. Avaliações quantitativas e predição das proporções de osso, músculo e gordura da carcaça em ovinos. Rev. Bras. Zootec., v.39, p.1253-1260, 2000.

SILVA, D.J.; QUEIROZ, A.C. Análise de Alimentos: métodos químicos e biológicos. 3.ed. Viçosa: UFV, 2002. 235p.

SIQUEIRA, E.R.; SIMÕES, C.D.; FERNANDES, S. Efeito do sexo e do peso ao abate sobre a produção de carne de cordeiro. I. Velocidade de crescimento, caracteres quantitativo da carcaça, pH da carne e resultado econômico. Rev. Bras. Zootec., v.30. p.844- 848, 2001.

THOMPSON, J.M., BUTTERFIELD, R.M. Food intake, growth and body composition in Australian Merino sheep selected for high and low weaning weight. 4. Partitioning of dissected and chemical fat in the body. Anim. Prod., v.45, p.49-60, 1987.

ZAMIRI, M.J.; IZADIFARD, J. Relationships of fat-tail weight with fat-tail measurements and carcass characteristics of Mehraban and Ghezel rams. Small Rum. Res., v.26, p.261-266, 1997.

ZAPATA, J.F.F.; NOGUEIRA, C.M.; SEABRA, L.M.A. et al. Composição centesimal e lipídica da carne de ovinos do Nordeste Brasileiro. Cienc. Rural, v.31, p.691-695, 2001.

ZEOLA, N.M.B.L.; SILVA SOBRINHO, A.G.; GONZAGA NETO, S. et al. Composição centesimal da carne de cordeiros submetidos a dieta com diferentes teores de concentrado. Cienc. Rural, v.34, p.253-257, 2004. 